\title{
Microstrip Antenna with Photographic Paper Substrate for WLAN
}

\author{
D.S. Marotkar*, P.L Zade \\ Yeshwantrao Chavan College of Engineering Nagpur, India
}

\begin{tabular}{l}
\hline \hline Article Info \\
\hline Article history: \\
Received Apr 9, 2018 \\
Revised Jun 15, 2018 \\
Accepted Jun 29, 2018 \\
\hline
\end{tabular}

\section{Keyword:}

Photographic paper

Terms microstrip antenna

WLAN

\begin{abstract}
In this paper a compact, flexible, Multiband antenna is designed. It is having flexible Substrate of photographic paper which makes the antenna conformal. The antenna with two $U$ slots cut in radiating patch is offset fed by microstrip lines gives the multiple bands of WLAN/WIMAX Application and two parasitic Elements improves the bandwidth of a typical microstrip antenna. The Measured results shows that the antenna resonates between Frequency band 2.10-2.95 GHz, 3.35-3.54 GHz and 5.04-6.0Hz.which are used for application such as Bluetooth, Wi-Fi, Zigbee, ISM 2.4GHz, WLAN WiMAX, and WLAN 5.2GHz.
\end{abstract}

Copyright $(0) 2018$ Institute of Advanced Engineering and Science. All rights reserved.

\section{Corresponding Author:}

D.S. Marotkar,

Yeshwantrao Chavan College of Engineering Nagpur

739/A Mehidibag Road, Chittagong, Bangladesh, India.

\section{INTRODUCTION}

Demand for compact and multifunctional wireless communication systems has spurred the development of multiband and wideband antennas with small size. Microstrip patch antennas are widely used in this regard as they offer compactness, a low profile, light weight, and economical efficiency. However, the microstrip patch antenna is limited by its narrow operating bandwidth.

There are numerous and well-known methods to increase the band-width of antennas, including increase of the substrate thickness [1], the use of a low dielectric substrate [1], the use of various impedancematching and feeding techniques [2], the use of multiple resonators [3]-[7], and the use of slot antenna geometry [8]. However, the size antenna and the bandwidth of an antenna are generally mutually conflicting properties, that is, improvement of one of the characteristics normally results in degradation of the other.

Recently, several techniques have been proposed to enhance the bandwidth. In [9]-[11], utilizing the shorting pins or shorting walls on the unequal arms of a U-shaped patch, U-slot patch, or L-probe feed patch antennas, wideband and dual-band impedance bandwidth have been achieved with electrically small size.

In this work, a Multiband microstrip patch antenna employing parasitic elements is investigated. Two rectangular shaped parasitic elements are incorporated along the radiating edges of an offset fed rectangular patch antenna so as to get desirable bandwidth for WLAN. Due to the attractive characteristics, such as flexible, low cost and cellulose in nature, paper substrates have received much attention in recent years and become the most potential candidate of the wireless applications. Paper possesses great superiority than any other substrate for its wide availability, the high application the cheapest material and eco-friendly [4][5][6][10]. Paper is suited for reel-to-reel processing and employing fast process, such as inkjet printing, which can be used efficiently to print electronics on paper substrate [4]. In addition, the characteristics of low thickness and low weight make paper substrates applied to the wearable devices used for monitoring, cheap and flexible RFID tags [5]. The direct-write inkjet printing is an emerging technique by which the design structure is transferred 
directly to the substrate, unlike etching. This process is considered as a low-cost and no-waste fabrication process for electronics recently which do not need remove unwanted metal from substrate surface [12].

In this paper a multiband antenna is designed using inkjet printing method on photographic paper substrate for different applications of wireless communication. The design of the antenna is simulated and optimized by High Frequency Simulation Software (HFSS).

\section{GEOMETRY OF ANTENA}

The geometry of proposed antenna is shown in Figure 1. The antenna is of the size $60 \mathrm{~mm} X 56 \mathrm{~mm}$, contains two parasitic elements and is fed by a 50- $\Omega$ microstrip line. Both radiating patch, ground plane and the feed-line are printed on the photographic paper substrate, which has a thickness of $0.23 \mathrm{~mm}$ and a dielectric constant of 3.0. The microstrip line is offset in the horizontal direction from the middle of the ground plane. To excite three bands for the WLAN and WiMAX system, the partial radiating patch is modified by inserting a double U-slot strip. Two removed triangular bevel slots play an important role in the multiband characteristics and the coupling between the ground plane and the radiating patch [13].

Figure 2 shows the front view of proposed fabricated antenna and Figure 3 shows the bottom view of proposed fabricated antenna. A rectangular radiating patch with two removed triangles and offset fed is optimised to operate in frequency bands from $2.4 \mathrm{GHz}$ to $6 \mathrm{GHz}$. The double $\mathrm{U}$ slots gives three current path which results in three different frequency bands which covers the WLAN and WiMAX. The two parasitic elements are inserted in the proposed antenna design. The parasitic patch configuration improves the bandwidth of a typical microstrip antenna. The gain of the antenna is increased by using the gap-coupled configurations. In this type of antenna design, patches are placed near the edges of the original patch. These new patches may be coupled to the main patch electro-magnetically [14].

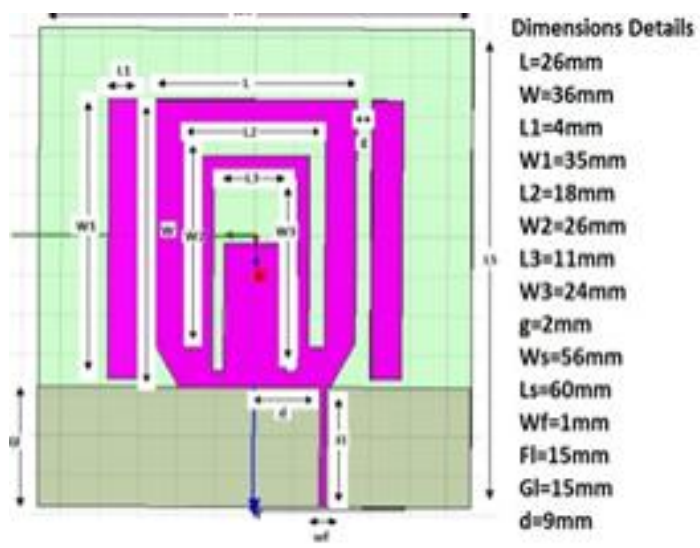

Figure 1. Geometry of Proposed Antena

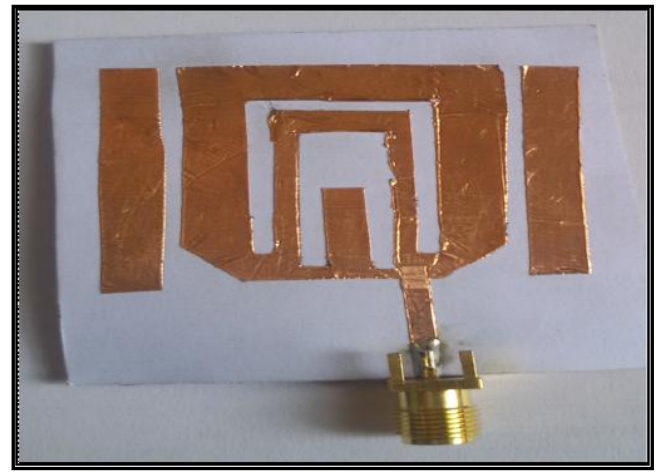

Figure 2. Front View of Fabricated Antenna

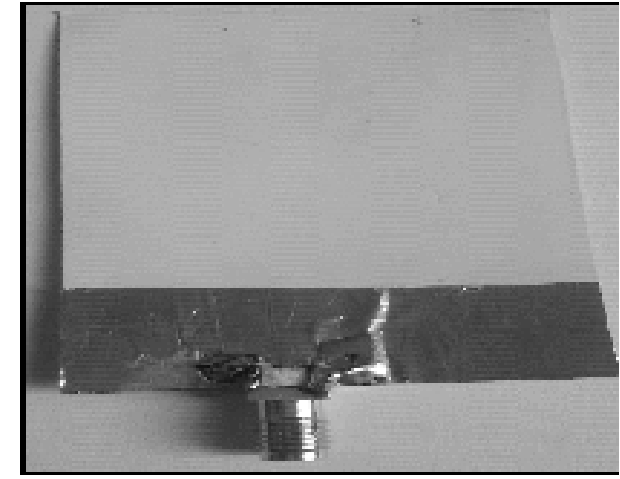

Figure 3. Bottom View of Fabricated Antenna 


\section{RESULTS AND DISCUSSION}

The performance analysis of the proposed antenna is done by HFSS. Then the antenna is fabricated and tested on Vector Network Analyser (VNA).The results on VNA of reflection coefficients S11 and VSWR are shown in Figure 4 and Figure 5. It can be seen that the antenna can operate in three frequency bands operates at $2.6(2.10-2.95), 3.45(3.35-3.54)$ and $5.5(5.04-6.0) \mathrm{GHz}$. These frequency bands cover the WLAN IEEE 802.11b (2.4-2.48 GHz), 802.11 a/n (5.15-5.35, 5.75-5.825 GHz), and WiMAX standards of band I (2.6$2.7 \mathrm{GHz})$, band II $(3.4-3.69 \mathrm{GHz})$, and band III $(5.25-5.825 \mathrm{GHz})$. Table 1 gives the comparison of simulated and measured values for the multiband microstrip antenna. The gain is $3.2 \mathrm{~dB}$ for simulation of antenna in HFSS and $2.8 \mathrm{~dB}$ for fabricated antenna. The gain of the antenna is not perfect, however, considering the length and width of the microstrip-fed line and the electromagnetic property of the photographic paper (the loss tangent is 0.06), the value is acceptable wholly. Table 2 shows the all the application of the proposed antenna and gives the details of the bandwidth and gain required for the particular application.

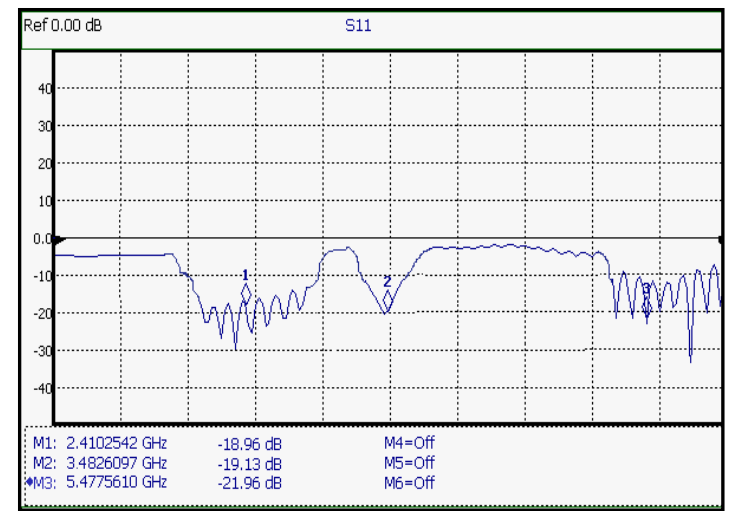

Figure 4. Return Loss of Fabricated Antenna on VNA

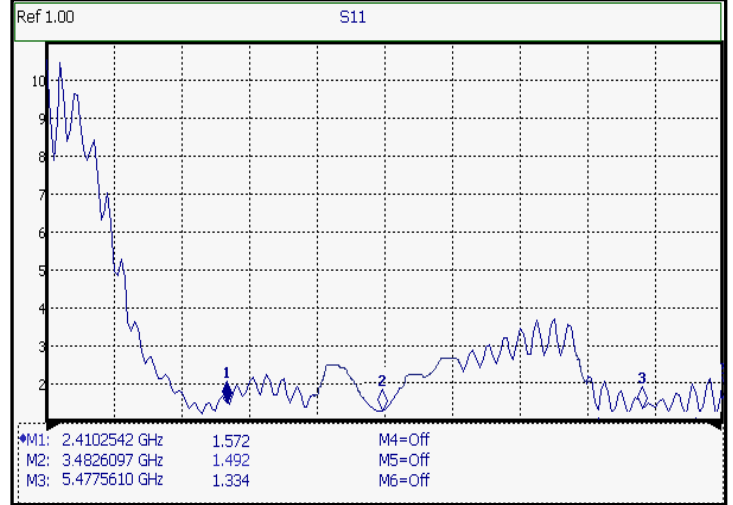

Figure 5. VSWR of Fabricated Antenna on VNA

Table 1. Comparison of Simulated and Measured Values Microstrip Antenna

\begin{tabular}{cccccc}
\hline Results & $\begin{array}{c}\text { Freq } \\
(\mathrm{GHz})\end{array}$ & $\begin{array}{c}\text { Return } \\
\text { loss } \\
(\mathrm{dB})\end{array}$ & VSWR & $\begin{array}{c}\text { Bandwi } \\
\text { dth } \\
(\mathrm{MHz})\end{array}$ & $\begin{array}{c}\text { Gain } \\
(\mathrm{dB})\end{array}$ \\
\hline $\begin{array}{c}\text { Simulated } \\
\text { Results }\end{array}$ & $2.20-3.10$ & -14.77 & 1.47 & 900 & \\
& $3.32-3.52$ & -12.06 & 1.68 & 200 & 3.2 \\
& $5.17-6.12$ & -13.09 & 1.56 & 950 & \\
Measured & $2.10-2.95$ & -18.96 & 1.33 & 850 & 2.8 \\
Results & $3.35-3.54$ & -19.13 & 1.49 & 190 & \\
& $5.04-6.0$ & -21.09 & 1.56 & 960 & \\
\hline
\end{tabular}

Table 2. Detail Requirements of Application of the Proposed Antenna

\begin{tabular}{cccc}
\hline Application & $\begin{array}{c}\text { Standard } \\
\text { frequency } \\
\text { band (MHz) }\end{array}$ & $\begin{array}{c}\text { Required } \\
\text { Bandwidth } \\
(\mathrm{MHz})\end{array}$ & $\begin{array}{c}\text { Standard } \\
\text { gain } \\
\text { Required }\end{array}$ \\
\hline Bluetooth & $2401-2480$ & 80 & $5.0 \mathrm{dBi}$ \\
Wi-Fi & $2400-2500$ & 100 & \\
ZigBee & $2410-2480$ & 70 & \\
ISM 2.4GHz & $2400-2483$ & 83 & \\
WLAN & & & \\
WiMAX & $3600-3800$ & 200 & \\
WLAN 5.2GHz & $5150-5350$ & 200 & \\
& & &
\end{tabular}




\section{CONCLUSION}

In this paper a Multiband microstrip offset fed antenna with parasitic element is designed and fabricated using photographic paper substrate. Results show that we achieved three bands which cover applications under WLAN /Wimax. It is clear that antenna with photographic paper substrate are promising candidate for wireless communication.

\section{REFERENCES}

[1] H. Schaubert, D. M. Pozar, A. Adrian, "Effect of microstrip antenna substrate thickness and permittivity: Comparison of theories and experiment," IEEE Trans. Antennas Propag., vol. AP-37, pp. 677-682, Jun. 1989.

[2] H. F. Pues, A. R. Van De Capelle. "An impedance-matching technique for increasing the bandwidth of microstrip antennas,” IEEE Trans. Antenna Propag., vol. AP-37, no. 11, pp. 1345-1354, Nov. 1989.

[3] D. M. Pozar, D. H. Schaubert, Microstrip Antennas. New York: IEEE press, 1995, pp. 155-166.

[4] H.F. Abutarboush., A. Shamim, "Paper-Based Inkjet-Printed Tri-Band U-Slot Monopole Antenna for Wireless Applications," IEEE Antennas and Wireless Propagation Letters, vol. 11, pp. 1234-1237, September 2012.

[5] Y. Amin, S. Prokkola, B. Shao, J. Hallstedt, H. Tehunen., Li-Rong, Z. "Inkjet Printed Paper Based Quadrate Bowtie Antenna For UHF RFID Tags", ICACT, pp15-18, February 2009.

[6] I. Kharrat, G. Eymin Petot Tourttollet, J-M.Duchamp, Ph.Benech, P.Xavier, T-P. Vuong, "Design And Realization Of Printed On Paper Antennas", European Coference on Antennas and Propagation (EuCAP), pp3199-3202, 7th 2013.

[7] S.-H. Wi, Y.-B. Sun, I.-S. Song, S.-H. Choa, I.-S. Koh, Y.-S. Lee, and J.-G. Yook, "Package-Level integrated antennas based on LTCC tech-nology," IEEE Trans. Antenna Propag., vol. 54, no. 8, pp. 2190-2197, Aug. 2006.

[8] S.-H. Wi, J.-M. Kim, T.-H. Yoo, H.-J. Lee, J.-Y. Park, J.-G. Yook, and H.-K. Park, "Bow-tie-shaped meander slot antenna for $5 \mathrm{GHz}$ application,” in Proc. IEEE Int. Symp. Antenna and Propagation, Jun. 2002, vol. 2, pp. 456-459.

[9] Y.-X. Guo, K.-M. Luk, K.-F. Lee, and R. Chair, "A quarter-wave U-shaped antenna with two unequal arms for wideband and dual frequency operation," IEEE Trans. Antennas Propag., vol. 50, pp. 1082-1087, Aug. 2002.

[10] B.S. Cook, A. Shamim, "Inkjet Printing of Novel Wideband and High Gain Antennas on Low-Cost Paper Substrate", IEEE Antennas And Wireless Propagation Letters, vol. 11, pp. 4148-4155, September 2012.

[11] R. Chair, C.-L. Mak, K.-F. Lee, K.-M. Luk, and A. A. Kishk, "Minia-ture wide-band half U-slot and half E-shaped patch antennas," IEEE Trans. Antennas Propag., vol. 53, pp. 2645-2652, Aug. 2005.

[12] X.L. Sun, S.W. Cheung, T.I.Yuk, "Design of Compact Antenna For 2.4/4.9/5.2/5.8-Ghz WLAN", Microwave and Optical Technology Letters, vol. 56, pp1360-1367, No. 6, June 2014.

[13] M. Li , X. Wang, W. Wang, L. Chen, "Paper-based Triple-Band Monopole Antenna for Next Generation Wireless Applications" 2014 IEEE 3rd Asia pacific conference on antenna and propagation, Harbin China.

[14] B. Rochani, R. Kumar Raj, "Design of Broadband Microstrip Patch Antenna with Parasitic Elements" International Journal of Advanced Research in Electrical, Electronics and Instrumentation Engineering, Vol. 3, Issue 6, June 2014. 